\title{
Conceptual Challenges of Observability for Transaction Sector in Economy
}

\author{
Evgeny A. Kuzmin \\ Research Fellow (Econ.), Ural State University of Economics, Russian Federation \\ Email:KuzminEA@gmail.com \\ Oksana N. Berdyugina
}

Assoc. Prof., Cand. Sci (Ped.), Tyumen State University, Russian Federation

Email: berdugina_igpi@mail.ru

Dmitri A. Karkh

Prof., Dr. Sci (Econ.), Ural State University of Economics, Russian Federation

Email: dkarh@mail.ru

\section{Doi:10.5901/mjss.2015.v6n4s3p391}

\section{Abstract}

Stimuli for the sustainable economic development are mainly kept owing to a balanced sectoral structure. An ideal ratio between the transformation (production) and transaction components helps to smooth shocks from crises of institutional reforms. A nature of institutional reforms has led to a conclusion of an evolutionary expansion both in terms of a number of institutions themselves (horizontal supplement), and the complexity in elaborating rules and regulations for the proper behaviour (vertical supplement). These and other causes logically lead to strengthening in the transaction sector. In terms of a missing conventional agreement on an evaluation of the transaction sector in economy, the paper has presented a review and the authors have systematized some typical errors and inconsistencies in approaches. In opposition to the "cost-based" evaluation method by J. Wallis and D. North, the authors have presented an available alternative method to measure the value of the transaction sector using "cost" parameters. The research has shown the efficiency of the used "cost" approach to the evaluation that eliminates significant errors in the recalculation of the volume of the transaction sector in the economy.

Keywords: Transaction costs, transaction sector, institutional reforms, sectoral structure of economy

\section{Introduction}

There is a belief that a content and characteristics of the transaction costs at a micro level of an economic agent are quite conventional to distinguish them with the highest credibility from other non-production costs of an enterprise. Although at an enterprise, there is a quite consistent scientific solution to this challenge, at a level of a branch or a territory we can describe an issue of cumulatively booked transaction costs with an obvious lack of a conventional agreement. It is harmonization of approaches, which is a focus of this research. It becomes clear that an evaluation of the so-called transaction sector in the economy includes a number of points important for methodology of institutionalism, the efficient development of which is restrained with available and clear contradictions between theoretical arguments and empirical counterarguments. This mainly relates to understanding of a role of the transaction sector as an integral part of the economic mechanism that provides continuity in production and an exchange associated with it. It is clear that an excessive or insufficient participation of the transaction sector poses risks for maintainance of the stable and sustainable development. Territorial or branch-specific imbalances in the sectoral structure only enchance the disproportionate development in some activities at the expence of others. This eventually leads to establishment of various forms of specialization.

Another aspect within the methodology is a nature and meaning of institutional reforms. With its emergence as an imulse responding to an external or internal disturbance, a transformation of an institutional structure each time goes under a direction of evolutionary expansion. Horizontal (in terms of an increase in a number of institutions) and vertical (in terms of deepening and sophistication of valid rules and norms of the proper behavior) transformations build up a power of presence of the transaction sector. All this takes place in an effort to neutralize the uncertainty, thereby producing a 
dangerous institutional trap, when the specific growth of the transaction costs, initially caused by the uncertainty of an economic situation, leads to institutional expansion (Kuzmin \& Barbakov, 2015), a natural consequence of which is the same uncertainty, but of a different kind.

Litvintseva (2005), pointed out to this issue saying that the transaction sector in the economy is an obstacle for the economic development and as a measure presenting "the recovery to some extent for the redistribution mechanism and setting limits for a level of evaluation for services in the transaction sector". This statement is highly controversial and debatable. However, it may be logically explained taking into account a number of remarks. To our mind, the transaction sector undoubtedly has a direct impact on the overall economic development. Nevertheless, in this regard it is not so much important to protect a growth in the transaction sector as a whole, as to set limits for an increase in that part of the transaction costs, which refers to the risk component, i.e. the recertative transaction costs. This suggested that the transaction costs in the specific calculus tend to a decrease with a simultaneous increase in a degree of adjustment of the economic system. Similar ideas were also found in Langlois. Langlois's scientific assumption that the "transaction costs lose their significance in the longer term" (Langlois, 1992) also includes an idea of a decrease in the transaction costs because of poor knowledge.

Zimmermann (2002) emphasizes, "the sum of the transaction costs seems to be a natural indicator to evaluate empirically the quality of institutions". We deeply believe that both in its absolute and relative form, the value of the transaction costs does not yet say of the quality of institutions. A more precise definition would be identification of massiveness regarding the institutional structure. Both with the high and low transaction costs, the institutional environment may be either qualitatively efficient, or may show signs of inefficiency. As the development of the institutional environment can be partially evaluated with the transaction costs (Note 1), it is worth referring to papers that present the issue of observability in the transaction sector in the economy, and especially to those that have laid the basis for a methodology of its calculation.

\section{Review of Literature}

In the review of academic papers on evaluation of the transaction sector in the economy, we have attempted to combine two fundamental concepts (Note 2), i.e. the original one and the cardinal one (Polovinkina, 2005). There are disagreements between them, which are a focus of an existing paradigm of opinions within the institutional theory. Within this paradigm, researchers every time face theoretical and empirical challenges regarding the observability of the transformation and transaction sectors in the economy.

\subsection{Concept of transaction costs}

Contemporary views on the transaction costs have their basis in papers by well-known theorists, who have laid the basis of research in the overhead costs spent by enterprises related to making transactions to sale goods (works, services).

Coase is considered a founder of this direction. According to many scientists (Folomiev, 2001; Efimova, 2008; Nureyev, 2005; Potapova, 2008; Dubrovsky, 1999; Popov, 2011; Allen, 2000; Parisi, 1999 etc.), he introduced the "transaction costs" concept in 1937. However, we have found that in "The nature of the firm", Coase (1937) had not used the "transaction costs" concept. A casual nature in views of scientists on introducing the "transaction costs" concept into the scientific use can be associated with later interpretations of Coase's findings and, at the same time, the arisen error in transmitting ideas of the price formation mechanism. Herewith, much later, in 1950, Marschak (1950) actively introduced the "transaction costs" term into the scientific use. His paper includes the first detailed description of a process, in which the transaction costs occur as the costs to be incurred for successful sales of a product. In other words, he referred the transaction costs to the "cost of a transaction" exactly.

Coase actually proposed a similar definition. His achievement is mostly the systematization of provisions on the costs incurred by enterprises in a competitive environment to make transactions. He also presented the price mechanism (Coase, 1937), where the overhead costs led to a price rise for a good. In terms of the enterprise functioning mechanics, Coase (Ibidem) designates it as "the cost of using the price mechanism", where the "marketing costs" actually have become a prototype for today's interpretation of the transaction costs.

A review of academic papers has allowed us finding that in the $19^{\text {th }}$ century before Coase's research, Marschak and Commons (Commons, 1931) from time to time and at the same time persistently had had ideas of the costs that arose in a field of an exchange of tangible objects. There is no doubt that the exchange as such includes a transfer of ownership rights, whereas parties at the same time incur some costs to secure such rights.

Considering an exchange mechanism as a principle of the transaction costs occurrence, we can distinguish 
papers, where their authors provide a scientific rationale for a change to a price for a good in virtue of a nature of the exchange and reasons for such change to its price. Earlier publications on this issue can be hardly found, but we can mention among them Menger's paper. Fully, we can call this paper one of the first, explaining "economic sacrifices" (Menger, 2007) to exchange goods. These economic sacrifices according to Menger include expenses for transportation, loss of time and others saying that without any significant economic sacrifice the exchange is an indifferent exchange operation, which he classifies as within the group of non-economic ones.

Today's ideas of a nature and a scope of the transaction costs are quite heterogeneous, but at the same time, they agree on their fundamental provisions. Taking into account that according to a broader definition, the transaction costs are "costs that accompany the relationships between economic agents", according to Kuz'minov, Bendukidze \& Yudkevich (2006), one can assume that their calculation may be produced by subtracting the profit and the production cost from a total revenue. There is a comprehensive definition on this issue by Arrow (1969). He says that the transaction costs are the costs to "maintain the business system on the go". In the end, they are the costs of the open economy with many economic agents, where the costs to maintain two-way-directed connections between them, as well as the costs for recording ("memorizing") these interactions, become the transaction costs. Contrary to an assumption by Kuzminov, Bendukidze and Yudkevich (2006), that the definition by Arrow "for an analysis is almost useless", in the context of their idea's operationality, we see in it a profound epistemological meaning.

\subsection{Concept of transaction sector}

A substantive review of literature from available sources has allowed us identifying that for the first time the concept similar to the transaction sector definition they used in the report by the USA National Bureau of Economic Research (1962), which mentioned the "sector-transaction category" term. However, this concept did not so much refer to the value of the transaction costs, as to a set of aggregates structured into groups regarding financial transactions. In other words, it describes the economic system from the very position of transactions instead of the costs incurred to make them.

Not referring anymore to the concept of the transaction sector, but to the term of transaction branches that are in the same etymological row, it is worth saying that the first mentionings of branches along with the "industry" term were in Florence. He specifies that "the industry can only be determined in some exchange operations, such as manufacturing, distribution, services, etc., and is usually a group of activity-specific enterprises that do not perform operations of another kind" (Florence, 1929). This clarification is essential to interprete and perceive in a correct way the transaction sector in terms of the institutional economy. As the transaction branches actually make the transaction sector, we can say that both these concepts are complementary.

In the today's understanding, the term "transaction branches" was used in Heller and Shell (1974), who used the expression "government production-transaction sector" and introduced such terms, as the "administrative feasibility set" and "efficiency production-cum-transaction plans". These concepts essentially transform theoretical approaches to understanding of a nature of the transaction costs. Indeed, in this context, they are used to describe the expenditures incurred by the state apparatus - the administrative costs mainly associated with implementation of the fiscal function. They are actually the transaction costs for governance and administration. It is particularly amazing that in Heller and Shell, there is a parallel between the taxation regime (sales tax rate) and the market development, to which this rate is applied. As a result, there is an important conclusion that the "administrative costs may be related to compensation of the costs incurred by the government and may lead to a closure of some markets and opening of others" (Heller \& Shell, 1974).

Approximately, in the same time, North and Thomas published their paper (long before the publication on evaluation of the transaction sector in the USA economy in 1870-1970). North and Thomas considered the economic development in a historical perspective and introduced into the scientific use the expression "analysis of a transaction sector" (North \& Thomas, 1973) regarding research in agricultural and industrial sectors in England and in the Europe in 16-18 centuries. This suggests that a method to calculate a share of the transaction sector had appeared a few years earlier than Wallis and North anticipated, and had already been tested in the retrospective economic analysis. Thus, the paper by Wallis and North is nothing else but a secondary presentation of the methodological apparatus to calculate the transaction sector in the economy with an exception that it has a detailed description of procedures and ways to calculate the transaction costs in the specifics of the USA economy structure. In this regard, significance of Wallis and North's research can be by no means underestimated, as it is there, where there is an evaluation of the transaction sector in the understanding common today. 


\section{Methodology}

\subsection{Cost-based and cost approaches}

It is well-known that there is a wide variety of research that differ either by methods to calculate the transaction costs and account them in the sectoral aspect, or by objects of an analysis. As the transaction costs are inherent to all economic agents, who are not the only participants in the system, it can be quite reasonable to assume that as objects of the analysis there may be two descriptors, very close to each other by their features. On the one hand, there is a territorial system of a macro or a meso level that combines many agents heterogeneous as of their affiliation, but at the same time functioning within a single economic mechanism (system). On the other hand, certain markets may serve as the object of the analysis with this category understood as a combination of homogeneous agents.

There had been repeated efforts to measure the transaction sector, but they had mostly had as their origin the same postulate that, in the end, had led to formation of the holistic approach, which has prevailed so far. Methodologies had as their basis that it was possible to estimate the transaction costs and the transaction sector itself using the socalled cost-based approach. Indeed, theoretical resistance of this approach is obvious. However, if we refer to empirical research, then we will find in them a lot of disadvantages and potential errors. There it will be necessary to learn more on the first methodologies, which have served as the foundations for this approach.

Many scientists presented the cost-based approach, but they all went from one research, i.e. the paper by Wallis and North (1986) entitled "Measuring the Transaction Sector in the American Economy 1870-1970". It became the basis for subsequent development of ideas on evaluation comparison between sectors in the economy. Over time, influenced by difficulties in empirical testing the methodology to calculate the value of the transaction sector has faced minor changes. The methodology found a feedback abroad and in other regions in papers by Dollery and Leong (1998) in Australia; Dagnino-Pastore, Farina J. \& Farina P. (1999) in Argentina; In Poland, there were Sulejewicz \& Graca (2005); there were Chobanov \& Egbert (2007) in Bulgaria, Van Dalen \& Van Vuuren (2005) in Denmark; Hazledine (2001) and Engelbrecht (2004) in the New Zealand and Australia; there were Datta Sam., Chakrabarti, Nilakantan \& Datta Saur. (2011) in India; Grigorieva \& Tarasova (2010) and Smirnov, Soshnikov, Vlasov \& Poberezhnyi (2005) in Russia; Poplavska (2006) in Ukraine, etc. All these research follow basic calculation algorithms.

Even with all things considered, we should not start a review of gained experience and an analysis of the arisen conflict between theoretical provisions and empirical conclusions from Wallis and North, but from Demsetz's publication (Demsetz, 1968). An opinion is common that he is an initiator of studies on the transaction sector as a separate economic group of branchers. However, our research has shown that before him the issue of measuring the transaction costs in the market had been a focus of Seyffert. I think that it was R. Seyffert, who was the first to attempt to define the transaction sector and give it quantitative characteristics.

Referring again to Demsetz, one can say that as the object of research he considered a separate market (the USA stock market). This fact mostly distinguishes this paper from many others. This very circumstance has allowed, finally, evaluating and to some extent presenting the transaction sector as a pool of enterprises that support the operation of the market. In cases when as the object of the analysis there is another market chosen, which is not isolated and transparent, it would be impossible to make reliable estimates.

Demsetz's paper is also remarkable because it makes important conclusions and allows outlining the transaction sector and identifying a role of the transaction costs in transactions. Thus, he makes a parallel between market [capital] imperfection and a size of enterprises [in case of borrowed funds]. A difference in the cost of the borrowed funds between large and small companies we may explained with differences in the cost of transactions, rather than with the capital market imperfection (Demsetz, 1968). Regarding the calculation of the transaction costs, Demsetz only made an emphasis on two components he considered. There are brokerage fees and a difference between the supply and the demand per financial asset. Other possible components, such as taxes on income from operations, the cost of custodial services, the cost for an access to the market and information he did not considered including in the transaction costs with all the obvious visibility of such affiliation.

The comprehensive expression saying that the "transaction costs are the cost to exchange property titles" (Ibidem) contributed into defining a regularity in a change to the value of the transaction costs with a change to frequency and a volume of transactions. Demsetz found and empirically confirmed that "the higher the frequency of transactions is, the lower the waiting cost in the trading queue of a predetermined length will be, and therefore, the lower the spread will be, which traders are willing to give to change positions in the trading queue" (Ibidem). The consequence of this is a change to the risk, when for a large number of assets, prices for which are relatively independent, the risk associated with the fluctuating value of the list of assets will be lower. Empirical calculations concerning a change to involvement of a 
professional in transactions with a change to the value confirmed Demsetz's conclusion of the costs to make transaction. This formed the basis for a quantitative measurement of the transaction sector as exemplified by the stock market. Although Demsetz's research belongs to those papers that concern the issue of the transaction sector evaluation, it does not give a concept or a clear indication saying how we ought to calculate the transaction costs and the general (total) value for the sector.

In addition to the findings, R. Seyffert presented the findings from the calculated value of the costs that accompanied trading in the West Germany in 1959: "the data show that per 116 groups of non-food products, the average cost of marketing was 49 percent of the final consumption price" (Seyffert, 1966). He also made calculations for other costs that enterprises incure on average. Thus, a share of transportation accounts for about $3.7 \%$, about $7.0 \%$ are taxes on turnover of goods and services. Finally, Seyffert concludes, "the market of operating costs from the end supplier (seller) is 38.3 percent of final consumer prices". Based on this conclusion, we tend to assume that the value of the transaction sector in estimates following Seyffert's methodology reaches the value of $56 \%$ of the total turnover of goods and services. The same research is the first to operate with cost values, and indeed provides the basis of the cost-based approach in calculating the transaction sector and defining its ratio towards transformation branches in the economy.

Such dividing of the transaction costs, as well as of other overhead expenses, further defines a functional relation between the costs incurred and the results obtained in an agents' activity. A fact becomes obvious that issues for a discuession in the cost approach methodology do not so much include a direct description and regulations of the transaction sector, as an approach to a calculation of its value, and a segregation of economic activities (industries). As a result, a review and a synthesis of various scientists' views, has helped to state and theoretically substantiate the proportionality hypothesis for the institutional structure (the transaction and non-transaction sectors in the economy), based on the distinctions fror the transaction costs (see Figure 1). The hypothesis appears to have a direct and inderect influence and can be represented in two versions.

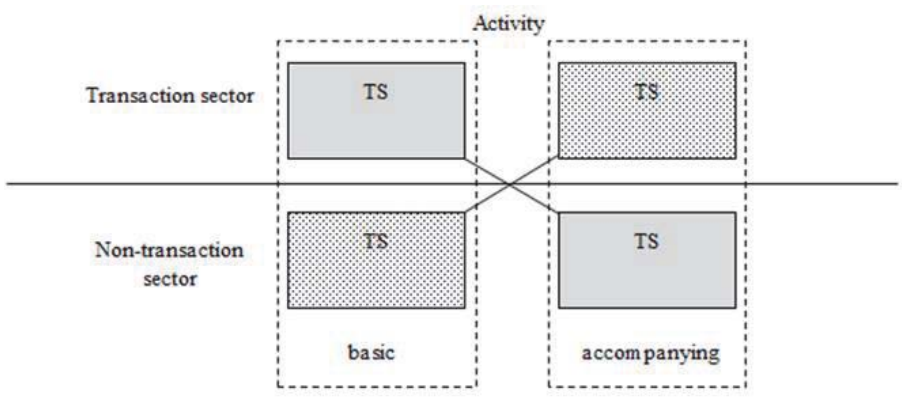

Figure 1. Representation of the transaction cost cross-distribution between sectors for the cost approach to an evaluation

First, as a research object, we can use a closed (non-opened) business system. Then, the hypothesis means that considering a relatively closed (non-opened) business system, one may detect an available identical equality in the market revenue from the transaction branches and the value of commercial and administrative expenses from the nontransaction branches, taking into account the reduction coefficient (cost transition coefficient).

Secondly, the business system can be open, and, in this case there are overlapping flows of the imported and exported transaction costs both in transaction and non-transactsion industries. Thus, in the second version of a direct interpretation, the proportionality hypothesis meaning might be expressed with the following thesis: within the open business system, a value of the market revenue in the residents' transaction brunches, increased by an amount of the non-residents' net revenue of economic agents in transaction brunches in transactions with residents within the business system, is identically equal to the commercial and administrative expenses (included into the transaction costs) in the residents' non-transactional branches, increased by an amount of the non-residents' net commercial and administrative expenses from transactions with residents, taking into account the reduction coefficient (cost transition coefficient).

Directly applied, the hypothesis lets us estimate a share of the commercial and administrative expenses incurred by economic agents in the non-transaction sector, that are internal (or external) in relation to business entities. Taking into account that they are the commercial and administrative expenses, that are involved, among other things in a calculation process of the transaction costs, we can reasonably conclude that a value of the commercial and administrative expenses, inherent to an economic agent, is a difference between the total transaction costs and the 
transaction costs, reduced by a value of their intermediate consumption.

Contrarily interpreted, the proportionality hypothesis has its grounds in an available partial specialization and an incomplete use of resources. An economic agent (or a brunch) are not net representatives of a particular economic activity, based on which we make a segregation into the transaction and non-transaction components. This, in turn, assumes an idea of a required transaction cost distinction with a target-oriebted attribute inherent to the economic entity. The transaction cost distinction using the target-oriented attribute is among three types of cost distinction, which we grounds in the research: first, this is the cost differentiation into the standard and recertative components; secondly, this is the transaction cost distinction into the net and intermediate ones. Thirdly, this is the cost differentiation based on a target-oriented correlation for an activity. If the cost distinction of the first type is a solution to the evaluation scientific challenge for the transaction costs associated with the risk and the uncertainty, then the cost distinction of the second and the third type is in line with an evidence for the proportionality hypothesis, showing a consequence from the institutional balance. In other words, a fact of the available institutional environment is expressed in the available transaction costs, which one economic agents incur in favor of the others. As a result, a balance identity of expenditures and revenues in the economy related to the transaction turnover lets us have a number of non-trivial conclusions on a form and a condition of the institutional structure.

\subsection{Evaluation of transaction sector by Wallis \& North}

Referring to the issue of a measurement of the transaction sector, Wallis and North (1986) specify that the costs for making transactions include the cost of labor force and production factors directly involved in transaction inplementation. To summarize, we can briefly describe the method of calculation for transaction services provided in the industrial sector (transformational function):

(1) it is defined that an activity is primarily related to the transactional functions;

(2) payroll to employees engaged in the transactional function is estimated.

Wallis and North make a particular emphasis on clarifying the fact that they attempt to calculate the value of the transaction services as an observed element of the transaction costs, formed at industrial enterprises. This essential observation suggests that such the cost-based approach by Wallis and North really and only makes it possible to calculate that share of the transaction sector, which accounts for the transaction services, whereas its real borders also include commodity-based transaction operations. The researchers themselves mention this saying that they "measure a level of the transaction services in the economy instead of a level of a total cost of a transaction" (Wallis \& North, 1986). Their very important comment should be added here, "as we focus on the transaction services, rather than the transaction costs, our estimates should not be regarded as an estimate of a level of the transaction costs in the economy ..." (Ibidem). However, other scientists easily adopted Wallis and North's ideas, having ignored this essential limitation and said of the measurement of the whole transaction sector.

To our mind, Wallis and North's approach assumes some criticism as inherently considers a single parameter, i.e. compensation payments and wages to those employees, who provide services in a field of the transactional function of enterprises.

Firstly, wages only present a part of the costs of the transaction services, although prevailing. The costs of the transaction services include several elements at least: the wage, above-mentioned; the cost to maintain premises where given services are provided; other costs, which allow recording a fact of servicing and the ownership for results of the services etc. As we can see, the wage cannot be fully an indicator of the cost of the transaction services, let alone applied for a calculation of the transaction sector. Besides, researchers themselves point to this, having concluded, "material procurement, coordination and monitoring of production factors and sales are included in the transaction costs. The separation of all the resources intended for a transaction from those that relate to a transformation, is now beyond our capabilities. We only focus on the labor costs associated with the transaction sector" (Ibidem).

Secondly, the evaluation of a ratio between the transaction sector and the transformational sector in the economy as seen by Wallis and North is performed by measuring the value of the labor costs towards the gross national product (GNP). They argue that this value "should be taken as a direct measure of the well-being" (Ibidem) and this is somewhat contrary to the way of calculation. Therefore, the best alternative would be an indicator of the gross national income (GNI), which also includes the remuneration. Nevertheless, they did not do this, and this leads to doubts regarding credibility of calculations. This is primarily caused by the fact that the wage is not the only parameter accounted in the GNI and let alone in the GNP. Thus, the total ratio of the value of compensation payments and remuneration in both transaction and non-transaction branches to the value of the GNP or the GNI will be always less than one, which in this case is unacceptable. 
There is no need to search in details for other possible errors and shortcomings in Wallis and North within this research. It is only worth referring to the statement that "the limited nature of the data and our method to estimate a share of resources allocated per employee [transactional function of enterprises] produce several possible imbalances in our estimates" (Ibidem). A search for explanations for such paradoxes is seemingly not our goal, and they can be explored in more details in papers with another subject.

\subsection{Factors of change to sectoral structure}

A large corpus of empirical data shows that the developed countries are described with an increased specific proportion of the transaction sector, which often prevails in the economic structure over the transformational one. For example, in Australia in 1991 it was 59.5\% (Dollery \& Leong, 1998); in the USA by $1990-62.8 \%$ (Ghertman, 1998), in Japan $55.0 \%$, in Germany $-63.9 \%$, in France $-63.9 \%$. The developing countries as a rule show a reverse trend. In Poland, in $1996-49.6 \%$ (Sulejewicz \& Graca, 2005), in Bulgaria by 1997 - 37.4\% (Chobanov \& Egbert, 2007), in Argentina in 1990 $-34.6 \%$ GDP (Dagnino-Pastore, Farina J. \& Farina P., 1999). There are several factors that explan this, to our mind.

The first among them is a transition from non-market to market relations. Herein, the important issue lies, i.e. accounting of the shadow sector in the economy, which is as known exactly higher in the countries in transition.

By its significance, the second factor is the specialist field and division of labor. It is not uncommon when the developing countries become raw materials or manufacturing appendage for the developed countries. At the same time, a turnover of finished goods is not carried out within a manufacturing country. Instead, it goes on within a country that is a bidding process organizer. A typical example of relevance for such phenomenon may be the today's role of China and Russia as a production site and an energy supplier, respectively.

Considering the factor of specialist field and division of labor, one can pay attention to the fact that its influene is associated with presence of at least two subfactors, which under certain conditions can be considered as independent. Firstly, this is the level of technology development understood so that opportunities to make new technology tools are limited and pre-defined with evolutionary processes in the economic development. Secondly, availability and development of the infrastructure. This subfactor determines whether an economic agent needs to bear additional costs to overcome infrastructure barriers that in the developed countries have been eliminated.

Competition development became another essential factor. In our view, this factor as such has led to a significant increase in the transaction costs. A struggle for the consumer forces to bear the additional costs to be involved in confrontation with other competing enterprises. Such costs more and more include expenses for marketing, data gathering and analysis, industry intelligence, business re-engineering and other tools to improve internal and external market competitiveness.

Wallis and North in their paper mention other factors of a change to the transaction sector and the transaction costs as a root cause for such changes. They say that there are "three main reasons, owing to which the transaction costs [for a period considered] have increased" (Wallis \& North, 1986): 1) an increase in a role of the transaction costs due to the "market expansion and increasing urbanization"; 2) "technology changes to production and transportation" (Wallis \& North, 1986) and 3) "reducing costs for a use of the political system". However, besides these factors as reasons for a growth in the transaction sector Wallis and North also refer to "deepened specialization and division of labor... the increased size of an enterprise and a role of the government regarding to the private sector". Dependence of the transaction costs on a level of the transaction asset specificity has been found in Williamson (1981), where he present three available decisive factors that determine the transaction costs, i.e. the uncertainty, the frequency of transactions and the asset specificity. Besides, Williamson $(1975 ; 1979)$ pays attention to limited rationality and the opportunistic behavior among economic agents, which may be an indirect confirmation of a direct connection between the transaction costs and the uncertainty. Similar ideas one may find in Klein, Crawford and Alchian (Klein \& Crawford, 1978).

\section{Discussion}

\subsection{Contradictions and errors in estimates of transaction sector in economy}

Wallis and North partly explain scientific and practical common use of the methodology to calculate the value of the transaction sector in the economy with no alternatives in it compared to concepts of the cost-based approach, which (concepts) unfortunately have not received their sufficient academic justification and reasoning. Even with all things considered, Wallis and North's approach to its full extent is not an example of rigorous methodology. Like any other method, it contains a number of limitations. Their violation or the non-strictly followed algorithm naturally lead to 
contradictions. It is refinement of a range of theoretical errors and empirical counterarguments obtained in practical testing of the methodology that is a focus of this research.

In this regard, it is not surprising that the approach by Wallis and North is actively replicated in attempts to define dimensions of the transaction sector. In a number of scientific publications, their methodology is reproduced in full, as in Dollery and Leong, Sulejewicz and Graca, Chobanov and Egbert, etc. Several scientists have taken it a step further and adjusted it to the specifics of an economic structure of those countries, for which they had made a calculation. Other scientists have only improved segregation between branches, but this have not been successful in each case. Let us consider in detail some examples of used Wallis and North's methodology.

We consider Van Dalen, Van Vuuren and Hazledine illustrative in this regard. They adjusted the basic methodology. In their publications, there are no traces of the tendency, which influences a revision of the content of the transaction branches. At the same time, the very approach to a calculation of the transaction sector has changed. Thus, a hallmark in Hazledine in making calculations for the economy in the New Zealand is accounting of the unemployed, who may be classified as the transaction sector.

There are deeper modifications to the methodology in works by scientists from Denmark, such as Van Dalen and Van Vuuren. Their paper is indeed the first research to measure and describe the Dutch transaction sector. In their assessment, they changed two fundamental points:

(1) Into the estimate of the transaction costs, they only include those costs that arise from a "use of markets" (Van Dalen \& Van Vuuren, 2005). At the same time, the transaction costs that arise within an enterprise are not considered in their paper. They call these costs as expenses aimed at "coordination of efforts to transform" [transformational function]. Thus, from this we can conclude that the external costs are only perceived as the transaction, whereas other costs do not have the similar content.

This assumption in an obvious and perfectly reasonable way that leads us to a conclusion that the methodology by Van Dalen and Van Vuuren is not totally harmonized. Making an analogy, one may find that the cost "of the use of markets" is nothing else but the "institutional expenses", which were measured by researchers. This rightly gives reasons to say that this methodology is mostly not perfect, but the approach itself to a calculation of the institutional costs is quite amazing.

(2) Van Dalen and Van Vuuren revised a criterion, with which they had defined the employment in the ransaction and non-transaction branches. If Wallis and North had a profession of manual and office workers as a correlation criterion, then Van Dalen and Van Vuuren as a unit of measurement had "workloads". They were the workloads, using which scientists determined, to what type of branches (transaction or transformatioaln) an employee belonged.

Another group of contradictions within the cost-based approach by Wallis and North includes attempts to resegregate branches by transactionness. A number of scientists wrongly and without proper grounds include in the transaction sector such branches in the economy, as transportation and communications, activities in a field of the information, research and development, education, providing social and private services (like in Poplavska (2006)). We believe that such a branche division may not be used for the evaluation. A nature of activities in the transaction branch implies that a result of works, completed works or provided services in the given industry is aimed at each possible facilitation for a transaction. Referring to the listed branches (in Poplavska), we can confidently say that they do not meet this principle. Hence, the calculations themselves can no longer be credible and believable.

Grigorieva (2008) and Tarasova (Grigorieva \& Tarasova, 2010) made similar efforts to change the content of branches for calculations. Into the transaction sector, they added such activities, as information and computing services and general business activities to ensure functioning of the market. However, we would like to pay attention to the point that including such activity as information and computing servicing into the transaction branches is highly controversial. On the one hand, this activity certainly influences intensity of transactions. But if we consider the information and computer servicing from another point of view, it will be obvious that the branch does not only provide services and implement works to the manufacturing sector, but also to other transaction branches (own use not considered). Therefore, it is impossible to say definitely that information and computing servicing can may be classified as the transaction sector.

We consider equally inconsistent the research by Anikina (2011), who unreasonably believes that the transaction costs are measured by the value of the costs to pay interest for used credit funds, differences in exchange rates, interests and penalties, the costs to recover damages (for non-fulfilled obligations), the amount of writed-off receivables and other expenses of this kind. Complex arguments by Anikina are worsened by erroneously divided activities that relate to the regional transaction sector, "... transportation, communication, other market and non-market services. Market services include construction... repair of motor vehicles, hotels and restaurants, rent and servicing. Non-market services ... 
education, public health and ... other housing, social and private services". Moreover, the evaluation of the transaction sector was based on the value of the gross domestic product attributable to the transaction branches. Erroneousness of this methodology is also practically assured.

\subsection{Reminiscence of Wallis \& North's model}

The cost-based approach to a calculation of the transaction sector in the economy, contained in Wallis and North, has found its reflection in research by scientists, who present their own solutions to this issue. An essential difference between them does not only give grounds to speak about the specifics of the evaluation method, but also of the perception of the transaction costs. In this regard, we may refer to a number of papers that show originality of alternative methods of calculation.

Using Germany (the West Germany) as an example, Bischoff and Bohnet made an empirical evaluation of the transaction sector in the economy in 1982-1993, applyibg the method submitted by Reichhardt (1995). In his paper, there is the concept to define the specific ratio of the transaction and non-transaction sectors. The main emphasis is not on remuneration to employees, but on a percentage of time, they spend on activities in these two sectors. In the paper, the author assumes that separation occurs by the professional basis, and quite reasonably states that each employee can perform both transaction, and transformation objectives.

The paper by Polski (2001) is alo noteworthy. It deals with a calculation of the transaction costs in banking in the USA in 1934-1998. It is noteworthy that the transaction costs for this market (which, to our mind, is classified as a separate open market) are calculated using a sum of two distinct components. The first component of the transaction costs for the banking system includes interest expenses regarding interest-bearing liabilities. The second component includes non-interest expenses, which consist of employee wages, outstanding bills and other expenses. In other expenses, according to Polski, we should include remuneration to top managers, legal service fees; the expenses for advertising; public relations; donations; information processing, communications; examination and auditing, etc. This highlights that factors within the territorial economy differ from those factors that are valid and relevant for separate markets.

Specificity of the transaction costs for the territorial economies and separate markets let us conclude that factors, which are catalysts of changes to the transaction costs, are unique. However, in all cases, there is that minimum set of parameters, which is taken into account in calculation of the transaction sector, such as, for example, the second component only, as seen by Polski.

Papers by Gabre-Madhin and Colby are other examples, where there is the specific constituent of the transaction costs for markets. We can describe in brief that according to Colby (1990) the specific constituent refers to the costs to complete field-specific works. To somewhat better extent, Gabre-Madhin (2001) explaines it. He managed to make an analysis of the transaction expenses using a commodity market - the grain market. The base component of the transaction costs, according to Gabre-Madhin, included the costs of the working time spent on a search for contractors (partners). He described the specific component with the cost of the working capital. Such an assumption of segregation and grouping of the costs, to our mind, is misleading to certain extent. This mainly relates to the costs of the working capital, as an activity in the commodity market should not be identical to the banking sector: the trading asset and the funds themselves to purchase it (the working capital) are simplification of the transformational function. It should be added here that the hypothesis of segregation is completely contrary to the findings from the research by Demsetz and Polski. Another important ground is that besides the costs for the search for contractors there are the costs for making a transaction and securing the property rights, which Gabre-Madhin did not take into account in his paper.

An unconventional approach to the issue of the transaction sector can be found in Sarajeva (2006), who moved away from traditional ways to define the transaction costs in the economy and applied for a description of "costs of transactions" by Hernando de Soto. As a result, it was possible to count the unproductive transaction costs by summing such costs, as: official rates for going through bureaucratic processes; the opportunity cost of time required to perform regulatory procedures. Then there were the direct costs of bribes for a successful completion of bureaucratic processes and preferential conditions; the tax costs; the costs for informal protection and contract enforcement; the opportunity cost of time spent on a search for reliable information on contractors, a check of their reliability, and other information costs and the costs to monitor contract execution.

There is a wide range of papers on theoretic and empirical measurements for the value of the transaction sector in the Russian economy. Such scientists, as Verenikin (1997), Kokorev (1996), Popov (Popov \& Gemby, 2011), Blokhin (2001) etc. were involved in research on this problematics at different times. Kokorev's paper "Institutional reforms in modern Russia: analysis of transaction costs dynamics" is fairly considered the first among such papers. In the 
methodology aspect, Kokorev actually followed ideas and provisions from the approach by Wallis and North on identification of the transaction costs. Herewith, he made their differentiation. He described a method to calculate the transaction costs at a micro level for business entities and a macro level for territorial economies. Thus, according to Kokorev, at the micro level such costs include overhead costs. This assumption was later criticized. The main obstacle here is a structure of the overhead costs, which does not mostly meet a condition of belonging to the transaction function. Regarding identification of the transaction sector at the macro level, Kokorev makes a hypothesis saying that the relationship between the transaction and transformation industries may be determined by studying specifics of the sales turnover. In our opinion, this assumption is not unreasonable. Hoewever, it does not only require a detailed analysis of the sales turnover, but also of such values, as, for example, the level (coefficient) of enterprise involvement in the primary activity (towards the industry).

Unlike many rsearchers, Blokhin applied for opportunities of the inter-branch balance within the system of national accounts to estimate the value of the transaction sector in the Russian economy. Thus, a review of 25 branches made in 1990-1997 gave Blokhin an opportunity to evaluate a contribution of the transaction branches, i.e. a sphere of circulation, including business and management, finance, credit and insurance. The researcher assumes that we can divide branch transaction costs into two types, i.e. full (multiplicative) and direct. Blokhin as a basis for his definition uses the matrix of coefficients of the full costs. This methodology eliminates many disadvantages of other approaches and provides more or less correct evaluations of the transaction sector. However, it is worth considering that not all the costs that can be attributed to the transaction were included into the calculation, so the calculation is approximative.

\section{Conclusion}

We have attempted to systematize ideas of the transaction sector and it has become obvious that the characteristic of the sector does not so much remain a controversial issue in this field, as the methodology to calculate its value and the way to segregate branches. These and many other theoretical and methodological issues eventually have led to a rise of such a scientific challenge, as correct accounting of dimensionality regarding the transaction sector in the economy (in conjunction with the transformation one) and identification of its aggregation structure by elements of the transaction costs.

The completed review of papers on the issue has enabled us pointing out to the alternative to Wallis and North's approach that had already considered traditional. Its idea comes down to a use of other parameters for evaluations, such as for example, the cost of transaction benefits. Our progressive withdrawal from Wallis and North's approach that is indeed cost-based opens the door to fundamental rethinking over a role and significance of the transaction sector in the economy. However, this will not exclude our further use of the cost-based approach. On the contrary, many ideas and provisions efficient for the institutionalism methodology owe to development of the cost-based approach. All this has allowed speaking with confidence of dualism in evaluation of the transaction sector in the economy. A way to have a solution to such dualism can be found to some extent in a direction of revised sectoral segregation of branches and a degree of commitment to an activity.

\section{Acknowledgements}

The research was supported by the Russian Humanitarian Scientific Foundation (RHSF) on "Development of a methodology for preventive uncertainty management for harmonization of structural changes in the process of reindustrialization of the economy", project № 14-32-01030.

\section{Notes}

Note 1. It is worth mentioning that development of the institutional environment is originally described with a measure of the uncertainty, which arises because of errors in harmonization of institutional rules and regulations, their incompleteness and inaccuracy. A conflict between economic agents in this context is a manifestation of a poor quality of institutions. Herewith, an amount or percentage of specific transaction costs spent on compliance with a valid institutional protocol does not explain how these costs change perception and an actual level of the environmental uncertainty.

Note 2. Identification of trends in changes to the value of the transaction sector in economics in a kind of a combination made of a share of transaction branches without a calculation of exact figures (ordinal approach); or an estimation of the exact value with a certain level of errors in calculations (cardinal approach). 


\section{References}

Allen, D. W. (2000). Transaction costs. In Encyclopedia of law and economics (pp. 893-926). Edward Elgar Press.

Anikina, N.A. (2011). Tools to control transaction costs at agricultural enterprises in regional economic cooperation system. Fundamental Research, 12, 618-622.

Arrow, K. (1969). The organization of economic activity: issues pertinent to the choice of market versus non-market allocation. The Analysis and Evaluation of Public Expenditure: The PPB System, 1, 47-64.

Blokhin, A. A. (2001). Institutional aspect of price analysis in the Russian reforms. Forecasting Issues, 1, 116-136.

Chobanov, G., \& Egbert, H. (2007). The rise of the transaction sector in the Bulgarian economy. Comparative Economic Studies, 49, 683-698.

Coase, R. H. (1937). The nature of the firm. Economica, 4 (16), 386-405. http://dx.doi.org/10.1111/j.1468-0335.1937.tb00002.x

Colby, B. G. (1990). Transaction costs and efficiency in water western allocation. American Journal of Agricultural Economics, 72, 11841192.

Commons, J. R. (1931). Institutional economics. American Economic Review, 21, 648-657.

Dagnino-Pastore, Farina J. M., \& Farina, P. E. (1999). Transaction costs in Argentina. Paper presented at International Society for New Institutional Economics.

Datta, S., Chakrabarti, M., Nilakantan, R., \& Datta, S. (2011). How does the transaction sector move in relation to the transformation sector during a development process? Insights from India's post-independence experiences. A Conference on Advances in Development Economics, Davidson Conference Center - USC, Los Angeles, California.

Demsetz, H. (1968). The Cost of transactin. The Quarterly Journal of Economics, 82 (1), 33-53.

Dollery, B., \& Leong, W.H. (1998). Measuring the transaction sector in the Australian economy. Australian Economic History Review, 38 (3), 207-231.

Dubrovsky, V. Zh. (1999). Properties and characteristics of business organization in light of modern theoretical concepts. Proceedings of the Ural State University of Economics, 1, 29-36.

Efimova, E. G. (2008). Economics. Moscow, MGIU.

Engelbrecht, H.-J. (2004). The transaction sector, the information economy, and economic growth in New Zealand: Taking Hazledine seriously. New Zealand Economic Papers, 38 (1), 87-99. http://dx.doi.org/10.1080/00779950409544395

Florence, P. S. (1929). The statistical method in economics and political science. London. Kegan Paul, Trench, Truberer \& Co.

Folomiev, A. N. (2001). Efficiency of management in context of economic transformation in Russia. Moscow: RAGS Publishing House.

Gabre-Madhin, Eleni Z. (2001). Market institutions, transaction costs, and social capital in the Ethiopian grain market. Washington, DC: International Food Policy Research Institute.

Ghertman, M. (1998). Measuring macro-economic transaction costs: a comparative perspective and possible policy implications. Working paper, Jouy en Josas. France: École des Hautes Études Commerciales. [Paper presented at the Second Annual Conference of the International Society for New Institutional Economics]

Grigorieva, E. M. (2008). On measurement and minimization of transaction costs in economics. Finance and Credit, 30, 49-53.

Grigorieva, E. M., \& Tarasova, Yu. A. (2010). Financial business structures: transformation influenced by market environment. Saint Petersburg: Petropolis Publishing House.

Hazledine, T. (2001). Measuring the New Zealand transaction sector, 1956-98, with an Australian Comparison. New Zealand Economic Papers, 35 (1), 77-100.

Heller, W. P., \& Shell, K. (1974). On optimal taxation with costly administration. American Economic Association, 64(2), 338-345.

Klein, B., \& Crawford, R. (1978). A vertical integration, appropriable rents, and the competitive contracting process. Journal of Law and Economics, 21, 297-326.

Kokorev, V. (1996). Institutional reforms in modern Russia: analysis of transaction costs dynamics. Issues of Economics, 12, 61-72.

Kuzmin, E. A., \& Barbakov, O. M. (2015). Institutional efficiency and processes of institutional changes (as seen by the Russian academic tradition). Asian Social Science, 11 (6), 163-170. http://dx.doi.org/10.5539/ass.v11n6p163

Kuz'minov, I. Ya., Bendukidze, K. A., \& Yudkevich, M. M. (2006). Course of institutional economics: institutions, networks, transaction costs, contracts. Moscow: GU VSHE Publishing House.

Langlois, R. N. (1992). Transaction cost economics in real time. Industrial and Corporate Change, 1 (1), 99-127. http://dx.doi.org/ 10.1093/icc/1.1.99

Litvintseva, G. P. (2005). Investment crisis because of non-compliance between structural and technology characteristics of economics and its institutional arrangements. In P. M. Nureyev, \& V. V. Dementieva (Eds.), Post-Soviet institutionalism (pp. 240-262). Donetsk: Chestnut.

Marschak, J. (1950). The Rationale of the demand for money and of 'money illusion'. Microeconomica, 2 (fasc. II), 71-100 [reprint in J. Marschak (1974). Economic information, decision, and prediction: selected essays (pp. 95-130). Springer].

Menger, C. (2007). Principles of economics. Ludwig von Mises Institute [translated reprint of C. Menger (1871). Grundsatze der Volkswirtschaftslehre].

North, D. C., \& Thomas, R. P. (1973). The rise of the Western world: A new economic history. Cambridge University Press. http://dx.doi. org/10.1017/CBO9780511819438

Nureyev, R. M. (2005). Course of microeconomics: college textbook. Moscow: Norma.

Parisi, F. (1999). Coase theorem and transaction cost economics in the law. In J.G. Backhaus, The Elgar companion to law and 
economics. Edward Elgar Publishing. http://dx.doi.org/10.4337/9781843768692.00009

Polovinkina, N. V. (2005). Methodological basis for transaction costs analysis. Bulletin of N. I. Lobachevsky Nizhny Novgorod University. Series: Economics and Finance, 1, 677-682.

Polski, M. M. (2001). Measuring transaction costs and institutional change in the US commercial banking industry. Mimeo: Indiana University.

Poplavska, Zh. V. (2006). Transactional sector in Ukrain: assessment and development issues. Proceedings of DonNTU, Series: Economic, 103-1, 89-94.

Popov, E. V., \& Gemby, M. N. (2011). Region transactional sector. monograph. Yekaterinburg: loE of UB of RAS.

Popov, E. V. (2011). Transactions. Ekaterinburg: Ural Branch of Russian Academy of Sciences.

Potapova, I. S. (2008). History of economic thought. Moscow: MGIU.

Reichhardt, M. (1995). Der beitrag des transaktionskostenansatzes zu einer theorie der transformation von wirtschaftsordnungen. Frankfurt: Peter Lang. (Eine theoretische analyse mit empirischer untersuchung gesamtwirtschaftlicher transaktionskosten am beispiel West- und Ostdeutschlands).

Sarajeva, I. N. (2006). Challenges in assessing level of transaction costs in business sector of economics in Ukraine. Proceedings of DonNTU. Series: Economics, 103-2, 153-159.

Seyffert, R. (1966). Kosten der wege und der distribution industriell gefertigten konsumwaren. Cologne and Opladen: Westdeutscher. Verlag.

Smirnov, V. T., Soshnikov, I. V., Vlasov, F. B., \& Poberezhnyi, P. A. (2005). Socio-economic institutions of Russia. Moscow: Machinebuilding-1.

Sulejewicz, A., \& Graca, P. (2005). Measuring the transaction sector in the Polish economy, 1996-2002. Paper presented at the $9^{\text {th }}$ Annual Conference of International Society for New Institutional Economics. Barcelona.

The Flow-of-funds approach to social accounting: appraisal, analysis, and applications: a report of the National Bureau of Economic Research. (1962). Conference on Research in Income and Wealth, National Bureau of Economic Research. Princeton University Press.

Van Dalen, H. P., \& Van Vuuren, A. P. (2005). Greasing the wheels of trade: a profile of the Dutch transaction sector. De Economist, 153 (2), 139-165. http://dx.doi.org/10.1007/s10645-005-2933-4

Verenikin, A. O. (1997). Transaction costs in market economy. Moscow University Bulletin. Ser. 6. Economics, 3, 52-64.

Wallis, J. J., \& North, D. (1986). Measuring the transaction sector in the American economy, 1870-1970. In S. L. Engerman, \& R. E. Gallman (Eds.), Long-term factors in American economic growth (pp. 95-162). University of Chicago Press.

Williamson, O. E., (1975). Markets and hierachies: analysis and antitrust implications. New York: Free Press.

Williamson, O. E. (1979). Transaction cost economies: the governance of contractual relations. Journal of Law and Economics, 22, 233261.

Williamson, O. E. (1981). The economics of organization. The transaction cost approach. American Journal of Sociology, 87 (3), 548 577. http://dx.doi.org/10.1086/227496

Zimmermann, K. F. (2002). Frontiers in economics. Springer. http://dx.doi.org/10.1007/978-3-540-24739-5 